\title{
"SIMPLES, ATRAHENTE E COMMOVENTE": O ENSINO DE HISTÓRIA NOS PROGRAMAS DOS GRUPOS ESCOLARES SERGIPANOS (1912-1924)
}

\author{
"SIMPLE, ATTRACTIVE AND MOVING": THE TEACHING OF HISTORY IN THE \\ PROGRAMS OF "SERGIPE" SCHOOL GROUPS (1912-1924)
}

Magno Francisco de Jesus Santos ${ }^{1}$

\begin{abstract}
RESUMO: Nos últimos decênios, as discussões acerca do ensino de história foram responsáveis pela constituição de um novo e fértil campo de pesquisa histórica. Todavia, apesar dos importantes avanços em determinadas temáticas, ainda é visível a escassez de estudos sobre a História do ensino de História em períodos anteriores à segunda metade do século XX. Este artigo tem como escopo problematizar as propostas de Ensino de História no estado de Sergipe no período entre 1912 e 1924, por meio dos programas de ensino atribuídos aos grupos escolares. Com isso, torna-se possível entender algumas vicissitudes sobre a História ensinada para a infância brasileira ao longo dos dois últimos decênios da Primeira República, bem como a compreensão sobre a relação entre o ensino de História pátria e o de História regional.
\end{abstract}

Palavras-chave: Ensino de História. Programas escolares. Grupos escolares.Sergipe.

\begin{abstract}
In recent decades, discussions about the history teaching were responsible for the constitution of a new and fertile field of history research. However, in spite of important advances in certain themes, the scarcity of studies about the history of history teaching in periods prior to the second half of the 20th century is still visible. This article aims to problematize the proposals of history teaching in the state of Sergipe in the period between 1912 and 1924, through the teaching programs assigned to the school groups. With this, it becomes possible to understand some vicissitudes about the history taught for the Brazilian childhood, throughout the First Republic, as well as the understanding about the relation between the teaching of homeland history and the teaching of regional history.
\end{abstract}

Key words: History Teaching. School programs. School groups. Sergipe.

\section{Introdução}

\footnotetext{
1 Professor Adjunto do Departamento de História, do Programa de Pós-Graduação em História e do Programa de Pós-Graduação em Ensino de História da Universidade Federal do Rio Grande do Norte. Doutor em História pela História da Universidade Federal Fluminense
} 
As Histórias são decerto este espelho no qual o historiador não cessou jamais de olhar, de interrogar-se sobre sua própria identidade: ele é esse que olha e é olhado, questionador-questionado - enfim, sempre conduzido a declinar seus títulos e qualidades (HARTOG, 2004, p. 40).

A assertiva defendida por François Hartog revela o historiador como o pesquisador irrequieto, vivenciando um dilema na encruzilhada: volta-se para o passado, mas não deixa de olhar para o seu próprio tempo. O ato de olhar e ser olhado, questionar e ser questionado é uma questão inerente ao ofício do historiador e expressa uma dimensão relevante acerca das suas investigações, nas quais as temáticas são gestadas a partir das inquietudes enfrentadas no seu próprio tempo.

O uso da metáfora do espelho por Hartog é também uma questão elucidativa para compreender como o processo de construção do conhecimento encontra-se imbricado pelas questões gestadas no tempo presente. A emergência da história-problema desfez a ilusão de existir um passado inócuo, distante e pronto para ser destrinchado pelo historiador. Pelo contrário, tornou-se notório como o passado é constantemente reinventado, repensado pelo âmbito da História. Desse modo, partindo desta inquietação, torna-se salutar pensar a pesquisa histórica levando-se em consideração algumas questões atinentes à operação historiográfica, a partir do lugar de produção, das práticas investigativas e da escrita (CERTEAU, 2006, p. 66).

No âmbito das investigações sobre o Ensino de História no Brasil, um dos campos privilegiados tem sido o da História do Ensino de História. Circe Bittencourt (2011, p. 84) salienta como os estudos acerca da "história do ensino de história têm sido objeto de pesquisas conforme levantamento das produções sobre o ensino de história a partir da década de 1980". Essa produção tem como cerne a reflexão acerca dos diferentes projetos atinentes à formação da disciplina entre a primeira metade do século XIX e o alvorecer do século XXI. ${ }^{2}$

\footnotetext{
2 Temos como exemplos da produção sobre a História do Ensino de História os textos de Bittencourt (1990, 2008), Freitas (2006, 2010), Ângela de Castro Gomes (2015), Cristiani Bereta da Silva (2014) e Marcelo Magalhães e Rebeca Gontijo (2013).
} 
Considerando a longa trajetória da História como disciplina escolar na sociedade brasileira, a pesquisadora Maria Auxiliadora Schmidt apresentou uma proposta de periodização para o Ensino de História no país:

\begin{abstract}
Com base nesse conceito e partir de investigações já realizadas em manuais destinados a professores e em propostas curriculares, produzidos no Brasil, foram sistematizados elementos para construção da seguinte periodização do ensino de História no Brasil: construção do código disciplinar da história no Brasil (1838-1931); consolidação do código disciplinar da história no Brasil (19311971); crise do código disciplinar da história no Brasil (19711984); reconstrução do código disciplinar da história no Brasil (1984-?) (SCHMIDT, 2012, p. 78).
\end{abstract}

Partindo desta periodização, torna-se possível pensar no processo de construção do código disciplinar atinente à História, bem como a identificação de possíveis fissuras promovidas a partir do período republicano com a demanda por uma História regional. Partindo dessa divisão, temos neste artigo o intuito de problematizar o Ensino de História ao longo dois últimos decênios da Primeira República, com o propósito de identificar as mudanças em relação às temáticas, abordagens e à própria concepção da disciplina no âmbito escolar. Com isso, estaremos contribuindo para a compreensão da História ensinada como um processo histórico, marcada por rupturas e continuidades, bem como pela apropriação de novas interpretações atinentes ao passado.

Este artigo tem como foco as propostas de Ensino de História nos programas dos grupos escolares de Sergipe ao longo dos últimos dois decênios da Primeira República, entre 1912 e 1924. Trata-se da análise de três programas escolares que demonstram a preocupação em fomentar o Ensino de História dentro de um parâmetro atrelado à construção da identidade patriótica ${ }^{3}$ ao fortalecimento dos saberes sobre o passado local. Neste sentido, debateremos como era proposta a articulação entre o ensino de História pátria e de História regional, como um elemento das reformas curriculares engendradas por políticos e intelectuais republicanos com inspiração federalista.

\footnotetext{
3 O civismo foi um dos principais elementos que norteou os currículos da disciplina História ao longo do período da Primeira República, com a valorização da ideia de pátria e dos valores republicanos.
} 
A discussão foi dividida em dois momentos. No primeiro, foi debatida a questão do ensino para a infância no âmbito dos grupos escolares, ou seja, como os programas de ensino se apropriavam da chamada pedagogia moderna e do método intuitivo 4 na disseminação de uma proposta tida como inovadora. Os grupos escolares, como instituições que formatavam um modelo espacial de escola moderna, também deveriam ser o espaço da irradiação de novas metodologias de ensino com o processo de disseminação de uma proposta de renovação pedagógica, associada à modernização empreendida pelo Estado republicano. No segundo momento, enfatizamos como o Ensino de História foi proposto nos programas dos grupos escolares, bem como as sugestões pedagógicas defendidas para o ensino da disciplina para as crianças.

\section{1. "Em tom de narrações de lar": os grupos escolares e a escolarização da infância}

O emergir do século $X X$ foi marcado pelas preocupações atinentes ao processo de modernização do ensino público brasileiro, especialmente no tocante à educação da infância. Era necessário promover o aumento do número de crianças na escola e combater as elevadas taxas de analfabetismo no país, pois tais cifras elucidavam as fragilidades do sistema político republicano, com a ineficiência na consolidação dos valores democráticos (SANTOS, 2013).

Para Rosa Fátima de Souza, um dos caminhos encontrados pelos intelectuais e políticos republicanos foi a disseminação do modelo de escola primária graduada, como ícone imagético do espaço escolar tido como civilizado. Nesse modelo de escola, os prédios deveriam ser grandiosos e expressariam os princípios da pedagogia moderna, por meio do método intuitivo (SOUZA, 1998). Tanto a questão arquitetônica como o método de

\footnotetext{
${ }^{4} \mathrm{O}$ método intuitivo surgiu na Alemanha, ainda no século XVIII. Todavia, a sua disseminação ocorreu ao longo do período oitocentista, com os discípulos de Pestalozzi, tanto na Europa como nos Estados Unidos. No Brasil, o método intuitivo teve como seu principal propagador o intelectual e político Rui Barbosa, que nas propostas de reformas educacionais da década de $1870($ ??), defendeu a renovação do método.
} 
ensino expressavam as inquietações no âmbito das políticas públicas de educação, ao longo da Primeira República, como um problema nacional.

No caso sergipano, o primeiro grupo escolar foi fundado nos idos de 1911, com um espaço anexo ao novo edifício da Escola Normal (SANTOS, 2013). Todavia, antes mesmo da fundação dessa instituição, já era perceptível a atuação de intelectuais vinculados ao campo da Educação em defesa da reformulação do ensino. Um caso elucidativo é o do professor Baltazar Góes 5 , em 1905, quando publicou suas "Apostillas pedagógicas", nas quais se apropriava do método de ensino de grandes mestres da educação (GÓES, 1905).

Uma das preocupações centrais dos intelectuais sergipanos era atinente ao processo de modernização do ensino, pois esse era visto como o percurso necessário à inserção do Brasil no rol das nações civilizadas, bem como o caminho para a legitimação do regime republicano por meio do aumento de eleitores. A escola passava a ser entendida como o espaço da redenção, de construção da civilização brasileira (SOUZA, 1998). Essa concepção era compartilhada por diferentes intelectuais envoltos no âmbito da instrução pública em Sergipe e estava presente nos programas de ensino estabelecidos para o estado. No programa de 1912, elaborado por Baltazar Góes, há uma defesa da relação entre a escola e a edificação dos valores civilizados:Cumpre avançarmos na estrada da civilização. Civilizar é dar expansão às faculdades naturaes do homem; é a festa perenne em que elle celebra a Verdade, o Bello, o Bem, ideal imorredouro, seguindo o qual nos encaminhamos para a perfectibilidade. A civilização é obra da Educação (GÓES, 1912 , p. 8).

De acordo com a premissa defendida por um dos pioneiros no processo de reformulação do ensino a partir da introdução do método intuitivo em Sergipe, a civilização foi compreendida como uma marcha, uma estrada a ser trilhada. Era um destino a ser alcançado pelos diferentes povos. Todavia, o guia nesse caminhar era a educação. A escola se tornava

\footnotetext{
${ }^{5}$ Baltazar Góes foi um dos principais entusiastas do movimento republicano em Sergipe. Nasceu em Itaporanga, província de Sergipe em 1853. Concluiu o ensino secundário no Colégio Atheneu Sergipense e posteriormente ocupou vários cargos públicos no governo provincial. Foi um dos criadores do Clube Republicano de Laranjeiras, ao lado de Felisbelo Freire e atuou na primeira junta governativa de Sergipe republicano. Atuou como docente de Língua Portuguesa da Escola Normal. Em 1905 passou a ser diretor da Instrução Pública. Em 1911 tornou-se o diretor do primeiro grupo escolar de Sergipe, o Grupo Modelo. Faleceu em 1914 (GUARANÁ, 1925, p. 41).
} 
o centro irradiador de valores que norteariam uma sociedade patriótica e "perfeita".

De acordo com Baltazar Góes, o ensino primário deveria ser respaldado no método intuitivo, partindo do simples para o complexo, do concreto para o abstrato, da experiência para a teoria. Essas questões estão presentes no seu programa de ensino. Mais do que enunciar os conteúdos atinentes a cada disciplina, o professor defendeu algumas propostas de exposição dos conteúdos, revelando a preocupação com a aprendizagem. Isso ocorre, por exemplo, na apresentação dos conteúdos das aulas de música:

\footnotetext{
Música.

Hymnos patrióticos: o nacional, o da independência, o da República, o sergipano, etc. Escholares: o do começo e encerramento na classe. De recreio e de trabalho (no recreio): o ferreiro, o remador, o marceneiro, o lavrador, o serrador; pequenos cânticos em movimento de marcha militar. Este programma é de todas as classes. A música escholar é aprendida de outiva na aula (GÓES, 1912, p. 8).
}

$\mathrm{Na}$ acepção de Baltazar Góes, os cânticos escolares deveriam ser vistos como instrumentos no processo de formação de um modelo de cidadão, com a disseminação de valores que norteariam o futuro trabalhador e o patriotismo. Em relação aos hinos patrióticos, chama atenção à apresentação de cânticos que norteariam uma das práticas centrais dos grupos escolares no processo de fortalecimento dos valores patrióticos: as festas cívicas com seus desfiles (FARIA FILHO, 2014). As aulas de música se tornavam uma ocasião de preparação dos alunos para o vasto calendário permeado por desfiles pelas ruas e ensaios nos pátios dos grupos (SILVA, 2014).

Além disso, o amplo repertório era constituído por hinos nacionais e estaduais, com uma explicitação da perspectiva federalista no ensino primário que perdurou por praticamente toda a Primeira República. Essa proposta apresentava a nação a partir das experiências estaduais. O hino sergipano deveria ser ensinado como um recurso no processo de invenção de uma visibilidade estadual, ou seja, a construção de um sentido para o espaço que era inventado pelo âmbito do ensino da Geografia e da História escolares. Nesta perspectiva, o hino sergipano se tornava um instrumento 
de disseminação do sentimento patriótico que transitava entre o nacional e o estadual. Era uma confirmação dos discursos de outras disciplinas.

Outra questão relevante na assertiva é atinente ao método de ensino. A aprendizagem deveria ocorrer em sala de aula por meio da oitiva. A audição dos cânticos nas aulas se tornava o mecanismo de aprendizagem, com a valorização da experiência do professor. Baltazar de Araújo Góes defendia a ideia que o professor aprendia a ensinar por meio da experiência prática, ou seja, ensinando com prazer. Com isso, "para um mestre intelligente é o bastante. Ensinae com gosto e aprendereis a ensinar" (GÓES, 1905, p. 92).

Diante disso, pode-se afirmar que o programa de ensino dos grupos escolares, em 1912, revelava uma concepção na qual a instrução apresentava-se em diálogo com as demandas da vida prática. Para as aulas de trabalhos manuais, eram especificados os conteúdos para meninos e meninas, buscando atender às futuras demandas do trabalhador.

TRABALHOS MANUAES

Para meninas: costuras, bordados, tecidos, crochets, todos os trabalhos uteis, próprios do sexo. Para meninos e meninas: cartonagem, embrulhos, pacotes, nós, laçadas, tranças, dobragem, construcções, tudo o que for útil às futuras ocupações na vida comum (GÓES, 1912, p. 8).

O programa de ensino para os grupos escolares sergipanos, publicado em 1912, revelava uma conotação que atrelava o ensino à demanda da vida prática de um trabalhador urbano. Revela-se a formação de crianças com uma preocupação para os trabalhos domésticos (formação de meninas) e públicos do mundo urbano do alvorecer do século $X X$. Essa proposta de ensino é reveladora acerca do público predominante dos grupos escolares sergipanos no segundo decênio do século $X X$, com a reunião de filhos das camadas populares, de trabalhadores da capital sergipana. Essa concepção também é revelada na concepção acerca da aula de ginástica:

\section{GYMNÁSTICA}

Marchas, carreiras, saltos, brinquedos próprios da edade, practicados nos galpões e nos pateos, segundo as comodidades da eschola, com o fim de provocar e desenvolver alegremmente, a agilidade e a força, educar os órgãos de locomoção e trabalho; aliás, são exercícios callisthernicos (GÓES, 1912, p. 8). 
As aulas de ginástica deveriam cumprir com o desígnio de desenvolver nas crianças as habilidades de agilidade e força, bem como "educar os órgãos de locomoção e trabalho". Mais uma vez, percebe-se uma conotação prática atinente ao ensino. Os grupos escolares deveriam apresentar um processo educacional que priorizasse a formação do trabalhador, tornando-o apto para cumprior as suas funções no mundo urbano que se estruturava. No tocante ao método de ensino, a proposta consistia na valorização do corpo da criança como o elemento desencadeador das atividades físicas, com o uso do próprio peso. Essa proposta reverberava a concepção defendida pelo próprio Baltazar Góes, nos idos de 1905, ao afirmar que "nas escholas primárias a prática é o elemento essencial de todos os processos de ensinar" (GÓES, 1905, p. 6). A aprendizagem centralizava-se na perspectiva prática.

O programa enfatizava, também, os espaços onde deveria ocorrer o ensino. No caso das aulas de ginástica, o espaço estabelecido era o dos galpões e dos pátios. Certamente, nos edifícios construídos para os grupos escolares, a presença de pátios era tida como uma das principais inovações, atendendo às premissas de ensino da pedagogia moderna com o estabelecimento de espaços e períodos no âmbito da cultura escolar destinados ao recreio, ensaios de hinos patrióticos e aulas de ginástica sueca. Como bem elucidou António Viñao Frago, o espaço escolar era pensado pelos engenheiros como um programa, ou seja, constituía-se uma relação indissociável entre o espaço escolar e as práticas pedagógicas (VIÑAO FRAGO, 2002).

Além disso, o espaço da sala de aula também era redefinido, por meio da ação dos docentes no sentido de promover a distinção entre os alunos classificados como "adiantados" e "atrasados". O programa para o curso primário nos grupos escolares de 1917, elaborado por Helvécio de Andrade $^{6}$, preconiza pela intervenção do professor na definição do espaço

\footnotetext{
${ }^{6}$ Helvécio de Andrade nasceu em 1864, em Capela, província de Sergipe. Formou-se pela Faculdade de Medicina da Bahia em 1886 e atuou em vários cargos públicos em Sergipe. A partir de 1911 passou a ser lente da cadeira de Pedagogia, Pedologia e Higiene Escolar na Escola Normal de Sergipe. Atuou como diretor da Instrução Pública de Sergipe entre 1913 e 1918. Faleceu em 1940 (GUARANÁ, 1925, p. 218).
} 
escolar a partir do nível de conhecimento dos alunos. De acordo com as instruções gerais o ensino deveria ocorrer por meio do "methodo objetivo" e no primeiro ano,

Nos grupos cada classe consistirá um anno e será dividida em duas secções, pelo menos, conforme o adeantamento dos alumnos.

Na primeira secção da classe ou anno, os analphabetos, ou como taes considerados; na segunda, os que tiverem princípio de leitura, etc.

Juntamente com o horário observar-se-á:

a) As licções serão dadas e tomadas de pé, o professor em frente a classe ou ao quadro negro;

b) Terá o professor o cuidado de não dar as costas à classe a fim de que os alumnos não desviem a attenção do assumpto da liç̧ão, podendo utilizar-se de uma flecha para apontar o quadro negro;

c)Evitará o quanto possível as perguntas individuaes. $O$ alumno interrogado, não tendo respondido satisfactoriamente, o professor appellará para a secção ou classe, que corrigirá, se errar;

d) Nenhuma licção de coisas ou de leitura complementar será dada senão sobre objecto muito conhecido dos alumnos e que possa ser mostrado em natureza ou desenho (ANDRADE, 1917, p. 1).

Essas preconizações atinentes ao método de ensino são relevantes para a compreensão das propostas acerca da História Ensinada. Nos grupos escolares, o ensino primário era serial, com uma sala e professor disponíveis para cada série. Essa pode ser vista como uma das principais inovações desse modelo de instituição (SANTOS, 2013). Mesmo assim, o programa de ensino elaborado por Helvécio de Andrade defendia a intervenção do professor para promover a separação dos alunos em, pelo menos, mais dois grupos, de acordo com os conhecimentos do alunado.

A proposta de ensino para os grupos escolares era permeada pela sistematização das ações de professores e alunos, na qual o tempo escolar deveria ser controlado para a efetivação da aprendizagem. Isso exigia, também, a observação de um dos princípios básicos do método intuitivo, com o ensino que deveria ter como ponto de partida os elementos já conhecidos pelos alunos. Por esse motivo, o programa estabelecido por Helvécio de Andrade é todo permeado pela sugestão de objetos nas aulas, como frutas, bolas, palitos, pesos, mapas, globos, cartas de Parker e 
contadores mecânicos. Além disso, o programa apresentava uma lista de livros escolares que deveriam ser adotados no âmbito dos grupos escolares e das escolas isoladas, como pode ser observado no Quadro 1.

Quadro 1- Livros escolares adotados em 1917

\begin{tabular}{|l|l|}
\hline \multicolumn{1}{|c|}{ Livros Escolares } & \multicolumn{1}{c|}{ Autor } \\
\hline Cartilha Analytica & Arnold Barreto \\
\hline $\begin{array}{l}\text { Livros de Leitura (10 ao } \mathbf{4 0}^{\mathbf{0}} \\
\text { Minha Pátria }\end{array}$ & R. Pestana \\
\hline Contos Pátrios & Ana de Castro Osório \\
\hline Porque me ufano de meu paiz & Olavo Bilac e Henrique Maximiniano \\
\hline Autores Contemporâneos & João Ribeiro \\
\hline $\begin{array}{l}\text { Livro de Composição (para o } \\
\text { professor) }\end{array}$ & Manuel Bonfim e Olavo Bilac \\
\hline Arithmética elementar & Trajano e Ramón \\
\hline Cadernos de Arithmética & Ramón \\
\hline Gramáticas elementares & Pope, G. Andrade e João Ribeiro \\
\hline Geographia elementar & Lacerda \\
\hline $\begin{array}{l}\text { Licções de coisas (para o } \\
\text { professor) }\end{array}$ & Ruy Barbosa \\
\hline Caderno de desenho & - \\
\hline $\begin{array}{l}\text { Cadernos de calligraphia } \\
\text { vertical }\end{array}$ & - \\
\hline
\end{tabular}

Fonte: Adaptado de Andrade (1917, p. 20).

A lista de livros adotados pelo programa de ensino de Helvécio de Andrade tem como base alguns dos mais exitosos autores de livros escolares do início do século XX, como Afonso Celso, João Ribeiro, Olavo Bilac, Ruy Barbosa e Manuel Bonfim. Chama atenção o quantitativo de material destinado a atividades práticas, como os livros de leitura e os cadernos de caligrafia, desenho e aritmética. A presença desse material na lista de livros adotados reflete a preocupação com o ensino mais atrelado à experiência prática do que a questões especificamente teóricas. O ensino deveria ter a empiria como o seu cerne. Outra questão relevante é a ausência da indicação de livros escolares de História, apesar da existência da disciplina no programa, com o estabelecimento do ensino de conteúdos atinentes à História do Brasil e de Sergipe. Possivelmente, essa ausência 
poderia ter sido provocada por um esquecimento, ou, com maior plausibilidade, em decorrência do livro sugerido ao longo do programa ter sido publicado apenas em 1916. Tratava-se do livro "Meu Sergipe", publicado por Elias Montalvão.

Todavia, há outra questão que necessita ser observada. Os programas de ensino promoviam mudanças significativas na distribuição das disciplinas escolares, com a inclusão, supressão e retorno das mesmas de acordo com as propostas pensadas pelos respectivos diretores da instrução pública. Essas diferenças entre os programas de ensino reverberam a dinâmica acerca das políticas públicas de educação nos grupos escolares ao longo dos últimos decênios da Primeira República, bem como reforçam os pressupostos acerca do processo de constituição das identidades das disciplinas escolares, ou seja, "como os conteúdos são concebidos como entidades sui generis, próprios da classe escolar, independentes, numa certa medida, de toda realidade exterior a escola." (CHERVEL, 1990, p. 180). Neste sentido, torna-se salutar observar a distribuição das disciplinas nos três programas elaborados por Baltazar Góes, Helvécio de Andrade e Abdias Bezerra7, respectivamente em 1912, 1917 e 1924. Observe o Quadro 2:

\section{Quadro 2- Distribuição das disciplinas nos programas de 1912, 1917 e} 1924

\begin{tabular}{|c|c|c|c|}
\hline \multirow{3}{*}{ Série } & \multicolumn{3}{|c|}{ Programas } \\
\cline { 2 - 4 } & $\mathbf{1 9 1 2}$ & $\mathbf{1 9 1 7}$ & $\mathbf{1 9 2 4}$ \\
\hline \multirow{1}{*}{$\mathbf{a}$} & Língua Materna & Leitura e caligrafia & Português \\
\cline { 2 - 4 } & Aritmética & Aritmética & Aritmética \\
\cline { 2 - 4 } & Geografia & Desenho & Geografia \\
\cline { 2 - 4 } & História & Trabalhos Manuais & História \\
\cline { 2 - 4 } & Desenho & Música & Instrução Moral e \\
& & & Cívições de Coisas \\
\cline { 2 - 4 } & Música & Ginástica & Desenho \\
\cline { 2 - 4 } & Ginástica & - & Trabalhos Manuais \\
\cline { 2 - 4 } & Trabalhos Manuais & - &
\end{tabular}

\footnotetext{
${ }^{7}$ Abdias Bezerra nasceu na vila de Siriri, província de Sergipe, em 1880. Estudou no Atheneu Sergipense e chegou a ingressar na Escola Militar do Realengo, onde teve que abandonar em decorrência de seu envolvimento na revolta de 1904. Tornou-se professor do Atheneu Sergipense e, em 1923, passou a ocupar o cargo de diretor da Instrução Pública de Sergipe. Faleceu em 1944 (GUARANÁ, 1925, p. 2).
} 


\begin{tabular}{|c|c|c|c|}
\hline & Lições Gerais & - & - \\
\hline \multirow[t]{9}{*}{$2^{a}$} & Língua Materna & $\begin{array}{l}\text { Leitura, Caligrafia e } \\
\text { Composição }\end{array}$ & Português \\
\hline & Aritmética & Aritmética & Aritmética \\
\hline & Geografia & Geografia & Geografia \\
\hline & História & História & História \\
\hline & Desenho & Desenho & $\begin{array}{c}\text { Instrução Moral e } \\
\text { Cívica }\end{array}$ \\
\hline & Música & Música & Lições de Coisas \\
\hline & Ginástica & Ginástica & Desenho \\
\hline & Trabalhos Manuais & Trabalhos Manuais & Trabalhos Manuais \\
\hline & Lições Gerais & $\begin{array}{c}\text { Ciências Físicas, Naturais e } \\
\text { Educação }\end{array}$ & - \\
\hline \multirow[t]{9}{*}{$3^{a}$} & Língua Materna & $\begin{array}{c}\text { Leitura, Caligrafia e } \\
\text { Composição }\end{array}$ & Português \\
\hline & Aritmética & Aritmética & Aritmética \\
\hline & Geografia & Geografia & Geografia \\
\hline & História & História & História \\
\hline & Desenho & Desenho & $\begin{array}{c}\text { Instrução Moral e } \\
\text { Cívica }\end{array}$ \\
\hline & Música & Música & Lições de Coisas \\
\hline & Ginástica & Ginástica & Desenho \\
\hline & Trabalhos Manuais & Trabalhos Manuais & Trabalhos Manuais \\
\hline & Lições Gerais & $\begin{array}{c}\text { Ciências Físicas, Naturais e } \\
\text { Educação }\end{array}$ & - \\
\hline \multirow[t]{10}{*}{$4^{a}$} & Língua Materna & $\begin{array}{c}\text { Leitura, Caligrafia e } \\
\text { Composição }\end{array}$ & Português \\
\hline & Aritmética & Aritmética & Aritmética \\
\hline & Geografia & Geografia & Geografia \\
\hline & História & História & História \\
\hline & Desenho & Desenho & $\begin{array}{c}\text { Instrução Moral e } \\
\text { Cívica }\end{array}$ \\
\hline & Música & Música & $\begin{array}{c}\text { Ciências Físicas e } \\
\text { Naturais }\end{array}$ \\
\hline & Ginástica & Ginástica & Desenho \\
\hline & Trabalhos Manuais & Trabalhos Manuais & Trabalhos Manuais \\
\hline & Lições Gerais & $\begin{array}{c}\text { Ciências Físicas, Naturais e } \\
\text { Educação }\end{array}$ & - \\
\hline & $\begin{array}{c}\text { Educação Moral e } \\
\text { Cívica }\end{array}$ & & - \\
\hline \multirow[t]{9}{*}{$5^{a}$} & - & - & Português \\
\hline & - & - & Aritmética \\
\hline & - & - & Geografia \\
\hline & - & - & História \\
\hline & - & - & $\begin{array}{c}\text { Instrução Moral e } \\
\text { Cívica } \\
\end{array}$ \\
\hline & - & - & Economia Doméstica \\
\hline & - & - & $\begin{array}{c}\text { Ciências Físicas e } \\
\text { Naturais }\end{array}$ \\
\hline & - & - & Desenho \\
\hline & - & - & Trabalhos Manuais \\
\hline
\end{tabular}

História \& Ensino, Londrina, v. 24, n. 1, p. 165-197, jan./jun. 2018 
"Simples, atrahente e commovente": o ensino de História nos programas dos grupos escolares sergipanos (1912-1924)

\begin{tabular}{|c|c|c|c|}
\hline \multirow[t]{14}{*}{$6^{a}$} & - & - & Português \\
\hline & - & - & Aritmética \\
\hline & - & - & Geografia \\
\hline & - & - & História do Brasil \\
\hline & - & - & História Geral \\
\hline & - & - & $\begin{array}{c}\text { Instrução Moral e } \\
\text { Cívica }\end{array}$ \\
\hline & - & - & Economia Doméstica \\
\hline & - & - & $\begin{array}{c}\text { Ciências Físicas e } \\
\text { Naturais }\end{array}$ \\
\hline & - & - & Desenho \\
\hline & - & - & Trabalhos Manuais \\
\hline & - & - & Ginástica \\
\hline & - & - & Declamação \\
\hline & - & - & Canto Orfeônico \\
\hline & - & - & Religião \\
\hline
\end{tabular}

Fonte: Adaptado de Góes (1912), Andrade (1917), Bezerra (1924).

Partindo da concepção de que as disciplinas escolares são percebidas "como modos de transmissão cultural que se dirigem aos alunos" (CHERVEL, 1990, p. 186), torna-se possível compreender os programas de ensino dos grupos escolares sergipanos como um indício acerca da constituição disciplinar, bem como a oscilação dos conteúdos entre diferentes campos. Como assevera Ivor Goodson (1995, p. 43), "desde os primórdios, houve uma relação homóloga entre currículo e disciplina, aliando o currículo a uma ordem social". Isso implica em uma História social do currículo preocupada com determinantes sociais e políticas. A distribuição das disciplinas escolares revela concepções divergentes acerca do ensino, assim como as mudanças ocorridas no âmbito das políticas públicas de educação. Dentre essas mudanças, ressalta-se a reestruturação do ensino primário, em 1924, com a divisão em dois níveis: o elementar ( $1^{a}$ a $3^{a}$ série) e o superior ( $4^{a}$ a $6^{a}$ série). A inclusão de dois anos no ensino primário possibilitou uma melhor distribuição das disciplinas, assim como uma maior ênfase acerca da aprendizagem da leitura e escrita nos anos iniciais da vida escolar.

A comparação entre os três programas de ensino possibilita a compreensão acerca das continuidades de algumas disciplinas escolares, como Aritmética, Desenho e Trabalhos Manuais, com a presença em todas 
as séries dos três programas, sem alterações significativas no conteúdo e na nomenclatura. Em relação aos conteúdos de escrita e leitura, percebe-se uma continuidade dos conteúdos e da presença em todas as séries, mas com pequenas alterações na nomenclatura da disciplina, como Língua Materna, Leitura e Caligrafia e Português. Algo similar ocorreu em relação ao ensino das ciências naturais, especialmente nas últimas séries do curso primário, por meio de disciplinas como Lições Gerais, Lições de Coisas e Ciências Físicas e Naturais.

Outras disciplinas se destacaram pela perda de espaço na estrutura curricular dos grupos escolares. São os casos das aulas de Música e Ginástica, que, no programa de 1912, estavam inseridas em todas as séries e, no de 1924, apareceram apenas na $6^{a}$ série, sendo que a Música passava a ser designada como Canto Orfeônico. Em perspectiva inversa, outras disciplinas apresentaram um significativo aumento de sua relevância no currículo. Trata-se da Instrução Moral e Cívica, que, no programa de 1912, aparecia apenas na última série e, no de 1924, tornou-se disciplina presente em todas as séries. Sem dúvidas, esse protagonismo disciplinar revela uma iniciativa dos intelectuais brasileiros em relação ao processo de fortalecimento do patriotismo como instrumento da reinvenção da identidade nacional. ${ }^{8}$ Essa hipótese é corroborada pela lista de livros escolares adotados em 1917, com um predomínio de leituras cívicas que extrapolavam o campo disciplinar, com o ensino de Leitura e História.

Outras duas disciplinas apresentaram pequenas alterações em sua distribuição nos programas escolares. Foram os casos de Geografia e História, que estiveram presentes em todos os programas de ensino e em praticamente todas as séries. A exceção ocorreu no programa de 1917, no qual as duas disciplinas não foram inclusas no primeiro ano do curso primário. Essa ausência certamente revela uma preocupação com o método de ensino intuitivo, para o qual deve-se partir do simples para o complexo, do concreto para o abstrato, do empírico para o teórico. Neste sentido,

\footnotetext{
${ }^{8}$ Ao longo do período da Primeira República, é recorrente a presença de intelectuais e políticos defendendo o ensino com teor patriótico e cívico. Em Sergipe, isso se tornou mais presente ao longo da chamada tríade militar (1914-1922), momento no qual o estado teve três presidentes militares e que o civismo foi fomentado como política de Estado (SANTOS, 2013).
} 
Geografia e História eram concebidas como disciplinas mais complexas, o que exigiria um maior poder de abstração dos alunos para a aprendizagem.

Além disso, ressalta-se o fato de o programa de 1924 apresentar uma pulverização do conhecimento histórico em duas disciplinas distintas: História do Brasil e História Geral. A constituição desses dois campos para o ensino do conhecimento histórico se torna salutar para pensarmos acerca dos usos do passado no processo de reinvenção identitária, com o transitar entre a História nacional (com a inclusão de conteúdos regionais) e a universal, sendo esta marcada pela permanência da concepção oitocentista de cristandade ${ }^{9}$. Neste sentido, torna-se necessário discutir os conteúdos atinentes ao Ensino de História apresentados nos referidos programas.

\section{2. "Como as histórias do lar": o Ensino de História nos programas dos grupos escolares}

Os programas de ensino dos grupos escolares de Sergipe elucidavam os conteúdos a ser lecionados e apontavam para as questões metodológicas do ensino. Neste sentido, podemos entender esses registros documentais como evidências relevantes para a compreensão das propostas de Ensino de História ao longo da Primeira República. Além disso, percebe-se uma ênfase em atender às premissas epistemológicas do método intuitivo, que propunha partir dos elementos próximos e conhecidos para os distantes e desconhecidos. No programa de 1912, elaborado por Baltazar Góes, os conteúdos a serem ensinados na primeira série propiciavam a valorização da História local, da população que vivia nas proximidades da escola.

Os acontecimentos mais importantes de influência feliz ou nefasta na vida da população do logar a que pertence a eschola; biografia dos homens que se celebrizaram na localidade, por bons ou maus. Estes exercícios devem ser feitos em linguagem chan, clara, correcta, em tom de narrações de lar, que o professor fará repetir por seus discípulos, ajudando-lhes a memória e corrigindo-Ihes os

\footnotetext{
${ }^{9}$ Apesar da mudança de nomenclatura, em alguns casos os conteúdos da História Universal eram o da antiga disciplina "História Sagrada", amplamente difundida no século XIX.
} 
defeitos de exposição e de linguagem. Attender à moralidade dos factos (GÓES, 1912, p. 3).

O ensino proposto no programa de 1912 era respaldado na lição moral, com a exposição de episódios da localidade que elucidassem exemplos a serem seguidos ou a serem evitados. A inserção da experiência histórica na vida escolar do aluno deveria partir da própria localidade. A História local deveria ser o cerne das primeiras exposições, ou seja, a sala de aula deveria transmutar-se em palco para os desfiles de heróis do cotidiano da localidade. Por esse motivo, a ênfase no uso das biografias de "homens célebres", "bons ou maus", para servirem de exemplo na formação das novas gerações da localidade, com destaque para a valorização da moralidade dos fatos.

No âmbito metodológico, o programa ressaltava a condução do professor no trato dos conteúdos, por meio da exposição como se fossem "narrações de lar" e com a repetição pelos discípulos. O ensino deveria ser respaldado na repetição, como instrumento de aprendizagem pautado na memorização, na retórica e na linguagem. Por esse motivo a exposição docente deveria ser realizada em linguagem "chan, clara e correcta". Tais recursos corroboram, em parte, com a concepção de Itamar Freitas acerca do Ensino de História no período da Primeira República, na qual ele revela uma perspectiva linear.

Essa variedade de objetos é a alegria de todo pesquisador, porque conserva a utopia de uma História total (História do todo) e supera as narrativas produzidas na primeira metade do século $X X$, que punham ênfase nas ideias de História, nos programas, currículos e compêndios (FREITAS, 2010, p. 9).

Essa concepção revela uma leitura na qual o Ensino de História era visto como um mecanismo de memorização dos grandes episódios de um passado nacional. Todavia, a proposta do programa expressa algumas fissuras acerca dessa interpretação, pois estabelecia o Ensino de História pátria respaldada na experiência local, com a elucidação da trajetória de homens que servissem como exemplos. A nação era pensada a partir da linearidade entre as experiências regionais e o nacional. No tocante à memorização, outras possibilidades podem ser enfatizadas, pois a proposta 
de ensino definida por Baltazar Góes também combatia a "História decorada".

\author{
História \\ (Nada decorado: leitura e explicações)
}

I. a) Descobrimento do Brasil; seus primeiros habitantes; colonização pelos portugueses. b) Reinado de D. João VI; sua volta a Portugal.

II. a) D. Pedro I, sua regência, perturbações do paiz; projecto de retirada; o fico, a independência, principaes personagens desses acontecimentos. b) D. Pedro I resolve retirar-se; a abdicação; D. Pedro II na menoridade; a Regência. c) Maioridade de D. Pedro II e seu reinado até a proclamação da República.

III. a) $\mathrm{O} 15$ de Novembro; Benjamin Constant, marechal Deodoro da Fonseca; b) O governo provisório, a constituição republicana, a bandeira; c) Os presidentes da República até nossos dias. - Este ensino deve ser feito como as histórias do lar, escrevendo e fazendo escrever no quadro a summa dos acontecimentos, especialmente o nome dos protagonistas (GÓES, 1912, p. 10-11).

A explicitação dos conteúdos de História para a segunda série foi antecedida pela informação de que o ensino não poderia ser decorado, mas sim, ter como lastro a leitura e a explicação. Isso demonstra uma preocupação em aproximar as discussões acerca do Ensino de História das inquietações sobre o método intuitivo, por meio de uma aprendizagem que ocorresse a partir dos sentidos da criança. A sugestão metodológica de ensino proposta buscava associar a narrativa histórica às conversas domésticas, ou seja, apesar de existir uma ênfase na trajetória dos chamados "grandes homens" do passado, a História poderia ser expressa por meio de uma exposição que se distanciasse das antigas preleções, aproximando-se do âmbito do lar. Por outro lado, todo o conteúdo desta série estava atrelado ao caráter biográfico, com um predomínio absoluto da personificação do passado nacional por meio da dicotomia entre fatos e heróis.

Além disso, a ênfase na leitura desse passado nacional revela uma conotação de continuidade da experiência histórica brasileira em relação à História de Portugal. O marco inicial era a chegada dos portugueses com as grandes navegações, seguidas pela colonização e pelo processo de independência, todo protagonizado pelos personagens lusitanos de D. João 
VI e D. Pedro I. Por fim, emergiam os atores atrelados ao tempo presente, com os protagonistas do governo republicano e a leitura dos símbolos nacionais. No ensino sobre a República, a pátria era apresentada como um elemento de culto, com a bandeira, a constituição e a lista de presidentes. Eram proposituras que dialogavam com as questões vigentes no processo de legitimação do governo republicano, com a valorização dos símbolos nacionais como recursos imagéticos dos novos tempos (CARVALHO, 1991). Com isso, apesar de haver uma evidente defesa de um modelo de ensino que rompesse com a memorização, a explicitação dos conteúdos respaldados na hegemonia de heróis acabava por reforçar a aprendizagem decorada. Eram heróis que deveriam ser cultuados, mas que no âmbito do ensino tornavam-se listas de presidentes, com a sucessão de governantes. Os conteúdos da terceira série elucidam essa perspectiva:

História

I. Revisão e ampliação do anno anterior, especialmente quanto ao período republicano.

II. Divisão da história de Sergipe. b) Resumo do período colonial até a capitania independente. c) Sergipe sob o regime imperial. d) Sergipe desde a proclamação da República até nossos dias (GÓES, 1912, p. 11).

Mesmo expressando uma crítica à memorização, o programa respaldava a necessidade de repetição dos conteúdos, com ênfase para a História republicana (MAGALHÃES; GONTIJO, 2013). Essa demanda por uma História dos feitos recentes ia além de uma questão pedagógica, na qual se privilegiava o passado próximo por ser de mais fácil compreensão para o alunado. Ela elucida uma conotação da disseminação de uma cultura política ${ }^{10}$ republicana projetada por intelectuais sergipanos que estiveram envolvidos na campanha republicana desde meados da década de 80 do século XIX, entre os quais se destacou o próprio Baltazar Góes. A República era a protagonista da assertiva sobre os novos tempos do Brasil. Se o

\footnotetext{
${ }^{10}$ De acordo com Serge Berstein, cultura política é "uma leitura comum e normativa do passado histórico com conotação positiva ou negativa [...] e supre ao mesmo tempo uma leitura comum do passado e uma projeção no futuro vivida em conjunto" (BERSTEIN, 1998, p. 351). Para Ângela de Castro Gomes, "são representações construídas por grupos sociais de dimensões variadas sobre sua própria história" (GOMES, 2007, p. 50).
} 
passado da nação poderia ser visto em uma temporalidade tripartite, o momento privilegiado era exatamente o último, dos tempos republicanos.

Esse modelo de periodização da História do Brasil também foi transplantado para a História regional. O passado sergipano também foi dividido em três momentos: colonial, imperial e republicano, em consonância com a leitura nacional. Isso reflete que a inclusão de uma leitura regional não inviabilizaria a edificação de uma memória nacional. Pelo contrário, era pensada como uma ação que reforçava essa identidade da nação, pois a experiência particular encontrava-se como elemento integrante da grande pátria.

Contudo, a inclusão da História de Sergipe entre os conteúdos da História pátria na terceira série do curso primário não pode ser vista como uma lógica de continuidade da proposta pedagógica respaldada no método intuitivo. Ela mostra-se como uma fresta, na qual o Ensino de História iniciava-se pela localidade e seus sujeitos, passava para o passado nacional e retornava para a História regional. Essa lógica pendular de organização dos conteúdos, no trânsito entre o local, nacional e regional, pode ser visto como uma questão inquietante. Afinal, o que teria provocado o intelectual republicano a se afastar dos cânones do método adotado como fio condutor da educação pública sergipana no processo de organização dos conteúdos? No primeiro momento, parece ser uma questão de enfatizar a relevância da História de Sergipe, sendo trabalhada quando os alunos já tivessem conhecimento dos episódios centrais da História pátria. Mesmo assim, essa hipótese seria totalmente contraditória com a proposta metodológica do ensino. Quem apresenta uma hipótese mais consistente é uma professora formada pela Escola Normal Livre do Rio de Janeiro. Trata-se da professora Esmeralda Masson de Azevedo, pedagoga e autora de inúmeros livros escolares ao longo do segundo decênio do século XX. Na apresentação de seu livro de História do Brasil, em 1916, ela expressou:

Julgo que o estudo da Historia Patria, em seus detalhes, pode começar no curso medio. Attendendo, porem, que muitas creanças deixam a escola antes de encetar este curso, é de justiça que levem para a vida pratica alguns conhecimentos da evolução do seu paiz, isto é, as mais rudimentares noções da Historia da nossa terra. Creio que acompanham o meu 
pensamento muitos collegas que, no tirocínio do magisterio, vêm as exigencias do ensino (AZEVEDO, 1916, p. 8).

De acordo com a professora primária, autora de livros de História para crianças, o ensino da disciplina deveria ser iniciado já na segunda série, em decorrência das elevadas taxas de evasão. Com isso, a inversão da ordem dos conteúdos no caso do programa de ensino para os grupos escolares sergipanos revelava uma preocupação similar ao de Esmeralda Masson de Azevedo, com a preocupação em lecionar conteúdos de História pátria para os alunos em um momento anterior ao abandono da vida escolar. Neste caso, mesmo com a evasão, a criança sairia da escola com algum conhecimento sobre o passado nacional. Por esse motivo, a História de Sergipe só aparecia na terceira série e era repetida na série seguinte, quando ocorria a "revisão e ampliação do programma do 30 anno" (GÓES, 1912 , p. 12).

Se a evasão era compreendida como um dos maiores entraves para a educação brasileira, o civismo disseminado nas escolas era o instrumento ideal para edificar uma pátria civilizada. Para Baltazar Góes, "o patriotismo não mata o altruísmo. Amar a pátria, exforçar por seu progresso, é um sentimento mui nobre de emulação, que nos leva a igualarmos as nações que admiramos e aplaudimos em suas altas conquistas" (GÓES, 1912, p. 15). Neste cenário, os símbolos nacionais eram espelhos que refletiam o patriotismo, pois "a bandeira nacional, deixa de ser uma tela, convertendose em symbolo de nosso valor, de nosso mérito; o seu aspecto afflagará sempre o nosso amor, o nosso enthusiasmo pela pátria" (GÓES, 1912, p. 15).

Diante deste panorama, percebe-se a escola constituída como um espaço de propagação dos valores patrióticos. O calendário escolar era pensado a partir das celebrações das festas cívicas, enquanto os corredores do edifício escolar passariam a ser entendidos como uma galeria dos grandes homens, dos exemplos formadores da nacionalidade. O programa de ensino de 1912 elencava algumas possibilidades atinentes à memória dos heróis do Brasil.

Serão organisados previamente, de accordo entre professores e o director dos grupos (ou entre os professores 
e a auctoridade da instrucção, nas escholas isoladas) programas próprios para a celebração das principaes festas nacionaes: 07 de Septembro - a independência; o 13 de Maio - remissão dos captivos; 015 de Novembro proclamação da República; a Bandeira Nacional; o 24 de Outubro - independência de Sergipe. Os professores procurarão formar em suas aulas pantheons ou galerias de retractos dos homens célebres nas letras, artes, indústrias, armas, na pedagogia, de preferencia os grandes homens de nossa pátria (GÓES, 1912, p. 15).

Tanto o calendário escolar quanto a galeria dos heróis reforçavam a memória da nação em confluência com a memória da constituição identitária do estado de Sergipe. Celebrava-se o passado dos feitos políticos e o da integração nacional, na qual a ordem era compreendida como a resultante da ação dos grandes homens. Em tempos iniciais do período do pós-abolição, marcados pela emergência de problemas acerca do destino da população liberta, o 13 de maio era comemorado como uma indulgência ou ato de perdão dos grandes homens. A elite política de origem europeia era o sujeito da História nacional.

A relação entre a História nacional e regional também aparecia diluída nos conteúdos do programa de ensino dos grupos escolares de 1917, elaborado por Helvécio de Andrade. A disciplina começava a ser lecionada apenas a partir da segunda série, elucidando uma preocupação com a aprendizagem de conteúdos tidos como abstratos e distantes da realidade dos alunos. Ao contrário da proposta pensada por Baltazar Góes, o ensino de História não partia da experiência local, mas sim de uma perspectiva regional, com a História de Sergipe, com o currículo pensado a partir da exposição dos conteúdos de um livro escolar, publicado em 1916, por Elias Montalvão. Assim, no segundo ano de ensino, o aluno teria o contato inicial com a disciplina História. Nela havia "leitura e reproducção pelo alumno e ligeiro comentário pelo professor do "Meu Sergipe" de E. Montalvão comentada a liç̧ão interrogue o professor a classe sobre os pontos principaes do trecho" (ANDRADE, 1917, p. 2). No terceiro anno, o ensino continuava com a ênfase na História de Sergipe, debatida ao longo do primeiro semestre, e adentrava o ensino sobre a História do Brasil, no segundo. 
História

10 semestre - Primeiros habitantes de Sergipe, a primeira capital, a nova capital, seu adeantamento. Creação da província, o 24 de Outubro. Principaes factos históricos até a República.

20 semestre - Descoberta do Brazil, os selvagens e seus costumes. Os descobridores deviam tel-os estimados antes que guerreal-os. Destruindo-os privaram o Brazil de seu elemento autochtone, cujo valor, altivez e inteligência não se pode negar. Os francezes, os hollandezes, os hespanhoes. Os brazileiros sempre estiveram unidos para defender a sua pátria.

N. B. Segundo o processo do "Meu Sergipe" o professor exporá, em 10 logar, o ponto, de modo simples, atrahente e comovente, como uma pequena historieta e depois interrogará a classe (ANDRADE, 1917, p. 17).

"Simples, atrahente e comovente" eram os qualitativos esperados para o método de exposição do professor acerca dos conteúdos históricos. Em relação aos conteúdos de História regional, a proposta tinha como preâmbulo a discussão sobre os primeiros povoadores da localidade, com a elucidação dos povos indígenas. Posteriormente, eram elencados os episódios tidos como mais relevantes na experiência histórica do estado, como a ambivalência entre as duas capitais, com uma sugestiva indicação em demonstrar o adiantamento de Aracaju em relação a São Cristóvão, bem como a enunciação de fatos em perspectiva cronológica até o período republicano. A História de Sergipe deveria ser lecionada como uma enunciação das efemérides.

Helvécio de Andrade adotou como modelo de ensino a metodologia de exposição vigente no livro publicado por Elias Montalvão, nos idos de 1916. O conteúdo seria exposto como uma "pequena historieta" e, posteriormente, ocorreria a interrogação da classe. Certamente, tratava-se de uma leitura na qual o livro escolar era compreendido como um guia do professor no processo de ensino, ou, como salienta Kazumi Munakata (2016, p. 124), "o livro didático é a transcrição do que era ensinado, ou que deveria ser ensinado, em cada momento da história da escolarização".

Evidentemente, essas questões pontuadas pelo diretor da instrução pública consistiam em orientações acerca do Ensino de História para os docentes que atuavam nos grupos escolares, que nem sempre eram seguidas pelos mesmos. Mesmo assim, a presença de tais orientações pode 
ser vista como indício das possíveis práticas de ensino nos últimos dois decênios da Primeira República. Desse modo, os livros escolares podem ser entendidos como repertórios disponíveis para a orientação das diferentes estratégias de apresentação dos conteúdos históricos e, principalmente, o instrumento de exposição dos conteúdos a serem lecionados. Diante dessa constatação, torna-se necessário pensar sobre quais seriam os livros escolares de História de Sergipe disponíveis para os docentes dos grupos escolares ao longo dos dois últimos decênios da Primeira República, e quais eram os pensadores da História que se preocupavam com a escrita da História regional para crianças no processo de formação das novas gerações de sergipanos. O período posterior ao golpe de 1889 foi profícuo na publicação de livros escolares com conteúdos históricos sobre Sergipe. Observe o Quadro 3:

\section{Quadro 3- Livros escolares com conteúdos de História de Sergipe publicados ao longo da Primeira República}

\begin{tabular}{|l|l|l|}
\hline \multicolumn{3}{|c|}{ Livros escolares sobre História } \\
\hline $\mathbf{A n o}$ & \multicolumn{1}{|c|}{ Título } & \multicolumn{1}{c|}{ Autor } \\
\hline $\mathbf{1 8 9 5}$ & Corographia de Sergipe & Severiano Cardoso \\
\hline $\mathbf{1 8 9 7}$ & $\begin{array}{l}\text { Corographia do Estado de } \\
\text { Sergipe }\end{array}$ & Luiz Carlos da Silva Lisboa \\
\hline $\mathbf{1 8 9 8}$ & Quadro Corográphico de Sergipe & Laudelino Freire \\
\hline $\mathbf{1 8 9 8}$ & Corographia de Sergipe & $\begin{array}{l}\text { Manuel dos Passos de Oliveira } \\
\text { Telles }\end{array}$ \\
\hline $\mathbf{1 8 9 8}$ & $\begin{array}{l}\text { História de Sergipe: resumo } \\
\text { didactico para uso das escolas } \\
\text { públicas primárias }\end{array}$ & $\begin{array}{l}\text { Laudelino Freire } \\
\text { e Corographia de Sergipe }\end{array}$ \\
\hline $\mathbf{1 9 1 6}$ & $\begin{array}{l}\text { Meu Sergipe: ensino de História } \\
\text { Elias Montalvão }\end{array}$ \\
\hline
\end{tabular}

Fonte: Adaptado de Santos (2014).

Os dados do Quadro III elucidam um cenário em que o emergir do período republicano foi permeado pela eclosão de livros escolares sobre Sergipe. O grande destaque foi a publicação de corografias, que constituía um campo disciplinar pautado na compreensão do todo pelo estudo das partes, ou seja, o estado de Sergipe era estudado a partir da descrição da Geografia física, dos elementos históricos e culturais de cada município. 
Apesar disso, para Marcos Lobato Martins, as corografias eram caracterizadas pela "frágil ou inexistente articulação entre história e geografia" (MARTINS, 2010, p. 141). O insurgir republicano, margeado pela demanda federalista, tornou a Corografia de Sergipe uma disciplina de considerável relevância nos programas escolares do último decênio do século XIX. Um sinal desse prestígio foi o estímulo do governo do estado para a publicação de livros escolares por meio da realização de concursos. Todavia, paulatinamente, no emergir do século XX, essa disciplina passou a perder espaço para as emergentes Geografia e História de Sergipe como disciplinas autônomas e de conteúdo específico, pelo menos no âmbito dos programas de ensino dos grupos escolares.

Entre os autores de livros escolares de História regional, destacavamse importantes intelectuais que já pesquisavam e escreviam sobre História, como Manuel dos Passos de Oliveira Telles e, principalmente, pensadores da História que se consagrariam como autores de livros escolares, como foi o caso de Severiano Cardoso, Elias Montalvão e o professor do Colégio Militar do Rio de Janeiro, Laudelino Freire, que, em 1903, escreveria um livro escolar de história do Brasil (FREIRE, 1903).

No tocante ao conteúdo de História do Brasil, o programa de ensino de Helvécio de Andrade elucidava a fundação da nacionalidade, com o protagonismo português e tendo como coadjuvante o indígena. Este foi tratado em perspectiva ambivalente. Era classificado como selvagem, mas dotado de valores morais, altivez e inteligência. Por tais valores, as guerras impostas pelos lusitanos deveriam ter sido evitadas. Contudo, o que desperta mais atenção é o fato de o programa apresentar o índio como elemento de um passado superado, pois foram destruídos e, com isso, "privou-se o Brasil de seu elemento autóctone". De acordo com o programa de ensino, os índios e seus costumes só existiam nos livros escolares de História. Era o passado superado da nação civilizada.

Além disso, também era apresentada uma leitura do passado marcada pela ideia de unidade, na qual a nacionalidade brasileira teria sido instituída em 1500, com a chegada dos portugueses. Por esse motivo, o diretor da instrução pública enuncia que "os brasileiros sempre estiveram 
unidos contra o invasor", mesmo que isso tivesse ocorrido nos idos do século XVI. Em tempos de guerra ${ }^{11}$, o patriotismo emergia no ensino como um elemento naturalmente construído e reforçado pela instrução escolar. A ênfase nas narrativas históricas bélicas também estava presente na enunciação dos conteúdos para a quarta série:

\begin{abstract}
História
Recapitulação do 30 anno. Capitanias. As Revoluções Patrióticas: mascates, emboabas, guerra hollandeza. Vultos principaes que nella se celebrizaram - Inconfidência mineira, etc, etc. - O Brasil a chegada de D. João 60. Progresso realizado. A volta. Independência. A guerra do Paraguay - A República.

Primeiro exposição do ponto - Depois interrogatório do professor (ANDRADE, 1917, p. 20).
\end{abstract}

O passado da nação era ensinado por meio da sucessão de conflitos, das lutas patrióticas. O período colonial foi elucidado como um campo de batalhas no processo de constituição da autonomia, com a unidade do povo brasileiro na luta contra o invasor. Era um percurso que tinha início com a chegada dos lusitanos e concluído com a República. Nessa história bélica, os fatos eram compreendidos por meio da ação dos chamados vultos. Eram os grandes homens os responsáveis pela construção dos episódios tidos como fatos históricos. Tudo isso deveria ser ensinado em aulas expositivas, seguidas por questionamentos para a turma. O Ensino de História, no programa de 1917, tinha como respaldo central a exposição dos conteúdos que, por sua vez, eram caracterizados pela elucidação de fatos e vultos históricos.

Essa concepção passou por significativas mudanças no programa de ensino, publicado em 1924, no governo de Graccho Cardoso, com o novo diretor da Instrução Pública, Abdias Bezerra. A História voltou a ser uma disciplina presente em todas as séries do curso primário, sendo lecionada desde o momento de inserção do aluno na vida escolar. Além disso, na primeira série, o ensino da disciplina voltava-se para a História local, com

${ }^{11}$ O Programa de ensino de 1917 foi publicado no período da Primeira Guerra Mundial (19141918). 
ênfase para a concepção de mudanças e continuidades no espaço próximo da escola. Aparentemente, a disciplina teria passado a ser compreendida em perspectiva similar à do programa de 1912. Todavia, é perceptível a inovação dos conteúdos, em que o ensino era iniciado com uma discussão conceitual, especialmente atinente à pátria.

História

Dar ao alumno a ideia de Pátria, por meio de palestras sobre o lugar onde elle nasceu, onde nasceram seus paes, etc.

Nome da Pátria e de seus descobridores.

Primitivos habitantes, usos e costumes.

Palestras entre professor e alumno sobre as bellezas e as riquezas naturaes da Pátria.

Recursos do Estado ou da localidade, particularmente.

Ramo da indústria de maior desenvolvimento na localidade.

Progressos e melhoramentos realizados no Estado, na localidade particularmente (BEZERRA, 1924, p. 2).

O Ensino de História, tido como conhecimento abstrato e complexo, na concepção de Abdias Bezerra, deveria ser discutido a partir da explicação dos seus conceitos norteadores, como a ideia de pátria. Todavia, isso não implicaria na inaplicabilidade do método intuitivo, pois a ideia, inicialmente abstrata, seria compreendida por meio de exemplos visíveis, como a natureza do país, as suas belezas e riquezas. Desse modo, o mundo dos conceitos, abstrato, era transmutado em uma visibilidade, dada a ver e passível de comprovação.

No tocante ao ensino, o método de exposição do conteúdo era pautado nas palestras. Era o retorno das chamadas preleções, nas quais o professor poderia intercalar diferentes escalas espaciais para a leitura sobre o passado, indo da nação para o local, passando pelo Estado. O sentimento patriótico deveria ser propulsado por meio da elucubração da grandiosidade da natureza e dos recursos que potencializavam um horizonte de expectativa (KOSELECK, 2006). Essa propositura de palestras perpassava por todo o programa. Em relação aos conteúdos da segunda série:

Recapitulação do $1^{\circ}$ grão.

Palestras sobre o descobrimento do Brasil e da América.

Primeiras expedições enviadas ao Brasil.

Martim Affonso. Caramuru. João Ramalho.

Meios de colonização. Capitanias (BEZERRA, 1924, p. 2-3). 
Dos conteúdos apresentados para a segunda série, destacou-se a inserção de temáticas atinentes à História da América em consonância com o ensino sobre o descobrimento, ou seja, uma tentativa de entender o passado nacional no contexto americano e não exclusivamente como apêndice da História europeia. Todavia, o ensino iniciado com a discussão acerca da História local era transmutado para a narrativa nacional, com o período mais distante do mundo da criança. Mais uma vez, esse deslocamento temporal e espacial pode ser entendido como uma fresta da preocupação com a urgência em lecionar História pátria antes do momento de maior evasão escolar. Na terceira série, aparecia um diálogo entre a nação e as regiões:

Recapitulação do $2^{\circ}$ grão.

Governos gerais - Thomé de Souza, Duarte da Costa, Mem de Sá.

Civilização, cathechese - jesuítas.

Fundação da cidade do Rio de Janeiro.

Brasil reino - D. João VI - Sua vinda ao Brasil e seu retorno a Portugal.

Primeiras ideias de independência do Brasil.

Primeiras ideias de República no Brasil.

D. Pedro I e D. Pedro II.

Sergipe - conquista e independência.

Primeira capital - razões da mudança.

Segunda capital - Seu progresso (BEZERRA, 1924, p. 3).

Percebe-se como o ensino era conduzido a partir de uma revisão dos conteúdos da série antecedente para assim retornar a apresentação de novos conteúdos. Os conteúdos listados explicitavam uma alternância entre governantes e fatos históricos. Chama a atenção a associação entre a civilização do país e a atuação da catequese jesuíta, interpretação vigente em muitos livros escolares do período ${ }^{12}$, bem como a sugestão de trabalho a partir da História das ideias.

Em relação à História regional, percebe-se o seu retorno no final da unidade como um complemento da história pátria, também enfatizando os feitos políticos com a conquista e independência (BITTENCOURT, 2009, p.

12 Podemos elencar como exemplos desta associação os livros escolares de Esmeralda Masson de Azevedo (1916) e o de Raphael Galanti (1911). 
169). Na quarta série, o ensino de história permanecia dividido entre os conteúdos nacionais e regionais.

Brasil. Descobrimento. Gentio. Colonização. Capitanias donatárias. Governos gerais. Palmares, emboabas e mascates. Inconfidência Mineira. Revoluções pernambucanas. Invazões hollandezas. Invazões francezas.

Sergipe - parte histórica. Factos circunstanciados (BEZERRA, 1924, p. 4).

Os conteúdos estabelecidos para a quarta série do curso primário eram deliberadamente uma repetição dos conteúdos ensinados nos três primeiros anos do curso primário elementar. A colonização do Brasil e de Sergipe era revisitada, sem apresentar nenhum conteúdo novo, tendo apenas como sugestão de mudança a ênfase no fato e não nos vultos. Era uma retomada da leitura na qual a nacionalidade teria sido fruto das investidas bélicas ao longo do período colonial. Algo similar ocorria com os conteúdos da quinta série:

Recapitulação do 40 grão.

Brasil - Independência do Brasil. Abdicação de D. Pedro I e de D. Pedro II.

Menoridade e Maioridade. Guerra do Paraguay.

Libertação dos escravos. Proclamação da República (BEZERRA, 1924, p. 5).

Os conteúdos atinentes à quinta série do curso primário superior elucidavam exclusivamente a História do Brasil, com uma revisão dos conteúdos anteriores e destaque para o período imperial. Os fatos elencados eram essencialmente da vida política da monarquia, incluindo a guerra do Paraguai e a "libertação dos escravos". Desse modo, não seria exagero entender o Ensino de História desta série como o resultado da atuação da família imperial. A conclusão do curso primário ocorria com uma inovação disciplinar, pois os conteúdos de história eram dissolvidos em duas disciplinas independentes: História do Brasil e História Geral.

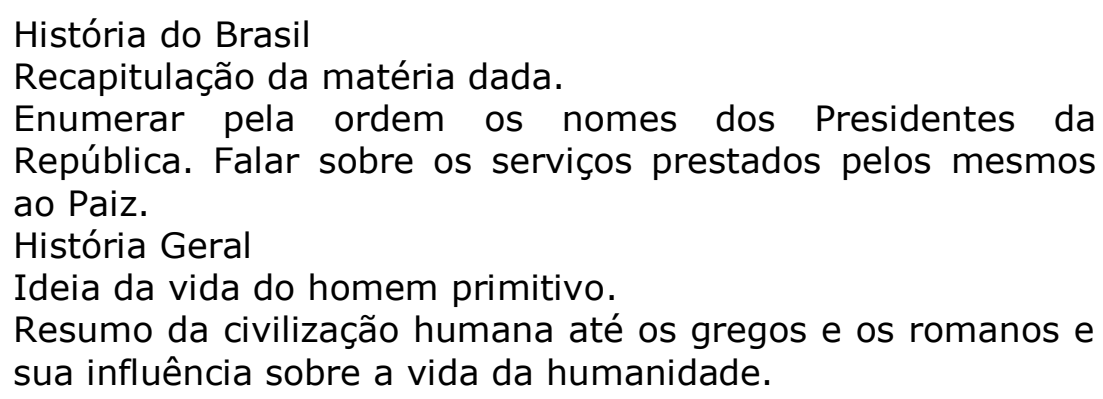


História do Christianismo.

Os grandes descobrimentos e as grandes invenções (BEZERRA, 1924, p. 5).

A inserção de duas disciplinas autônomas para discutir respectivamente a História do Brasil e a Geral era um recurso pensado no sentido de preparar o aluno para o curso secundário. A História do Brasil perpassava pelas discussões sobre o período republicano, com a enunciação dos presidentes e de seus "feitos" para o país. Pode ser entendido como uma estratégia de construir novos heróis, com a permanência do processo linear e cronológico. Em relação aos conteúdos de História geral, prevalecia o propósito de construção de uma leitura acerca da humanidade, com a busca das origens do homem tido como "primitivo" e adentrando ao mundo "civilizado", com gregos, romanos, cristãos e a emergência do mundo moderno a partir das chamadas "grandes navegações e grandes invenções". Neste sentido, se torna visível a leitura do passado da humanidade permeada por duas rupturas. A primeira seria entre o mundo primitivo e o civilizado, com a emergência da Grécia e Roma antigas. A segunda teria ocorrido com a emergência de uma civilização cristã, da qual o Brasil seria fruto.

\section{Considerações finais}

A análise acerca dos conteúdos de História apresentados nos programas de ensino dos grupos escolares sergipanos, publicados entre 1912 e 1924, elucida um contexto educacional permeado por rupturas, continuidades e reinvenções. As fissuras nas propostas de ensino da História para crianças em um período de apenas 12 anos podem ser vislumbradas por meio dos programas de ensino. Para Cristina Barroso,

Os programas revelam a forma com a qual estavam organizados os dispositivos de avaliação, de comportamento pedagógico e as práticas de sala de aula. As mudanças metodológicas, os conteúdos, as ordens, a tentativa de uniformizar o ensino primário nos grupos e escolas isoladas são características da influência do movimento modernizador (BARROSO, 2011, p. 103). 
Neste artigo, tornou-se possível compreender como as propostas de ensino de uma disciplina escolar atendiam a diferentes prerrogativas, como a do método pedagógico e das preocupações atinentes ao campo da aprendizagem, bem como às inquietações de intelectuais vinculados ao processo de constituição de uma nova cultura política. Partindo da premissa de que a cultura política busca construir uma leitura comum do passado e um projeto comum de futuro, os programas de ensino podem ser entendidos como instrumentos que extrapolam a cultura escolar e reverberam uma questão que não pode ser negada: a cultura escolar está em constante diálogo com a cultura da sociedade à qual pertence, incluindo projeções na política.

O Ensino de História, neste ínterim, passa a ser utilizado como uma normativa de leitura acerca do passado. Cria-se um passado comum, tanto em âmbito local, estadual e nacional. Forja-se uma identidade respaldada pelos laços de união entre os brasileiros contra o elemento invasor. Edificase um elo entre a nação em construção e o mundo europeu, tido como civilizado, silenciando as ressonâncias que pudessem prejudicar essa interpretação, como a atuação de negros e indígenas. O negro é apresentado como o ator libertado pelas ideias inovadoras. O índio emerge como o figurante de um passado imaginado e inexistente do tempo presente. Uma vaga lembrança de um Brasil selvagem e distante.

O Ensino de História destinado às crianças dos grupos escolares sergipanos era respaldado na ideia de palco no qual desfilavam os grandes homens, os vultos históricos atrelados a seus feitos. A História era tida como a ação de homens da política, grandes, destoantes da realidade dos alunos. A escola republicana, imbuída do papel cívico de combater o analfabetismo e formar novos eleitores para consolidar uma almejada democracia, transmutava-se em uma galeria para o culto dos vultos e dos fatos de uma história ensinada como historieta do lar: simples, comovente e atraente, mas também socialmente distante.

\section{Referências}

História \& Ensino, Londrina, v. 24, n. 1, p. 165-197, jan./jun. 2018 
ANDRADE, Helvécio de. Programma para o curso primário nos grupos escolares e escolas isoladas do Estado. Aracaju: Estado de Sergipe, 1917.

AZEVEDO, Esmeralda Masson. Licções de História do Brasil. 2. ed. Rio de Janeiro: Macedo, 1916.

BARROSO, Cristina de Almeida Valença Cunha. Reformas educacionais e a pedagogia moderna: mudanças no pensar e fazer pedagógico da Escola Normal (1911-1931). 2011. Tese (Doutorado em Educação) - UFBA, Salvador, 2011.

BERSTEIN, Serge. A cultura política. In: RIOUX, Jean-Pierre; SIRINELLI, Jean-François. Para uma História Cultural. Lisboa: Estampa, 1998.p. 349-363.

BEZERRA, Abdias. Programma para o curso primário elementar e superior de 1924. Aracaju: Estado de Sergipe, 1924.

BITTENCOURT, Circe Maria Fernandes. Ensino de História: fundamentos e métodos. 3. ed. São Paulo: Cortez, 2009.

BITTENCOURT, Circe Maria Fernandes. Pátria, civilização e trabalho: o ensino de História nas escolas paulistas (1917-1939). São Paulo: Loyola, 1990.

BITTENCOURT, Circe. Abordagens históricas sobre a história escolar. Educação e Realidade, Porto Alegre, v. 1, n. 36, p. 83-104, 2011.

BITTENCOURT, Circe. Livro didático e saber escolar (1810-1910). Belo Horizonte: Autêntica, 2008.

CARVALHO, José Murilo de. A formação das almas: o imaginário da república no Brasil. São Paulo: Companhia das Letras, 1991.

CERTEAU, Michel de. A operação historiográfica. In: . A escrita da história. Tradução Maria de Lourdes Menezes. Rio de Janeiro: Forense universitária, 2006.

CHERVEL, André. História das disciplinas escolares: reflexões sobre um campo de pesquisa. Teoria \& Educação, Porto Alegre, n. 2, p. 177-229, 1990.

FARIA FILHO, Luciano Mendes de. Dos pardieiros aos palácios: forma e cultura escolar em Belo Horizonte (1906-1918). 2. ed. Uberlândia: EDUFU, 2014. 
FREIRE, Laudelino. História de Sergipe: resumo didáctico para uso das escolas públicas primárias. Aracaju: Typographia Estado de Sergipe, 1898.

FREIRE, Laudelino. História do Brasil: resumo didáctico especialmente destinado à $3^{a}$ série do curso de adoptação do colégio militar. Revista Didáctica. Rio de Janeiro, jan./ out. 1903.

FREITAS, Itamar. Histórias do ensino de história no Brasil. 2. São Cristóvão: EDUFS, 2010. v. 2.

FREITAS, Itamar. Histórias do Ensino de História no Brasil. São Cristóvão: EDUFS, 2006. v.1.

GOES, Baltazar de Araújo. Pedagogia: apostillas de pedagogia: precedidas de noções de Psycologia colhida de bons mestres. Rio de Janeiro: Orosco, 1905.

GÓES, Baltazar de Araújo. Programma para o ensino primário, espacialmente os grupos escolares. Aracaju: Estado de Sergipe, 1912.

GOMES, Ângela de Castro. Cultura política e cultura histórica no Estado Novo. In: SOIHET, Rachel; GONTIJO, Rebeca; GOMES, Ângela de Castro. Culturas Políticas e leituras do passado: historiografia e ensino de História. Rio de Janeiro: Civilização Brasileira, 2007. p. 43-64.

GOMES, Ângela de Castro. História de chinelo: o ensino de História através do rádio no Brasil dos anos 1950. In: ROCHA, Helenice; MAGALHÃES, Marcelo; GONTIJO, Rebeca (Org.). O ensino de história em questão: cultura histórica, usos do passado. Rio de Janeiro: Ed. FGV, 2015.

GOODSON, Ivor. Currículo: teoria e história. Petrópolis: Vozes, 1995.

GUARANÁ, Armindo. Dicionário Biobibliográfico Sergipano. Rio de Janeiro: Pongetti, 1925.

HARTOG, François. Memória de Ulisses: narrativas sobre a fronteira na Grécia antiga. Tradução Jacyntho Lins Brandão. Belo Horizonte: Editora UFMG, 2004.

KOSELLECK, Reinhart. Futuro Passado: contribuição à semântica dos tempos históricos. Tradução Wilma Patrícia Maas e Carlos Almeida Pereira. Rio de Janeiro: Contraponto-Ed. PUC-Rio, 2006.

MAGALHÃES, Marcelo de Souza; GONTIJO, Rebeca. O presente como problema historiográfico na Primeira República em dois manuais escolares. Revista História Hoje, São Paulo, v. 2, n. 4, p. 81-101, 2013. 
MARTINS, Marcos Lobato. História Regional. In: PINSKY, Carla Bassanezi (Org.). Novos temas nas aulas de história. São Paulo: Contexto, 2010. p. 135-152.

MUNAKATA, Kazumi. O livro didático como indício da cultura escolar. Revista História da Educação, Porto Alegre, v. 20, n. 50, p. 119-138, 2016.

SANTOS, M. A Revista do Instituto Histórico e Geográfico de Sergipe e a invenção da historiografia sergipana. In: ALBUQUERQUE, S.; SANTOS, M.; SANTOS, A. (Org.). História, Memória e Comemorações na Casa de Sergipe: os 100 anos do IHGSE. Aracaju: IHGSE, 2014. p. 107-156.

SANTOS, Magno Francisco de Jesus. Ecos da Modernidade: a arquitetura dos grupos escolares sergipanos (1911-1926). São Cristóvão - SE: EDUFS, 2013.

SCHMIDT, Maria Auxiliadora Moreira dos Santos. História do ensino de história no Brasil: Uma proposta de periodização. Revista História da Educação, Porto Alegre, v. 16, n. 34, p. 73-91, 2012.

SILVA, Cristiani Bereta da (Org.). Educar para a nação: cultura política, nacionalização e ensino de história nas décadas de 1930 e 1940 . Curitiba: CRV, 2014.

SOUZA, Rosa Fátima de. Templos de Civilização: a implantação da escola primária graduada no estado de São Paulo (1889-1910). São Paulo: UNESP, 1998.

VIÑAO FRAGO, António. Do espaço escolar e da escolar como lugar: propostas e questões. In: FRAGO, Antonio Vrao; ESCOLANO, Austin. Currículo, espaço e subjetividade: a arquitetura como programa. Tradução Alfredo Veiga Neto. Rio de Janeiro: DP\&A, 2002. 